Rheumatoid arthritis - prognosis, predictors and outcome

\section{POS0435 CHARACTERISTICS AND 6-MONTH OUTCOMES AMONG REAL-WORLD PATIENTS WITH RHEUMATOID ARTHRITIS INITIATING UPADACITINIB: ANALYSIS FROM THE CORRONA REGISTRY}

J. M. Kremer ${ }^{1,2}$, N. Tundia ${ }^{3}$, R. McLean ${ }^{1}$, T. Blachley ${ }^{1}$, A. Maniccia ${ }^{3}$, D. A. Pappas $1,4 .{ }^{1}$ Corrona, LLC, Waltham, United States of America; ${ }^{2}$ Albany Medical College, The Center for Rheumatology, Albany, United States of America; ${ }^{3}$ AbbVie Inc., North Chicago, United States of America; ${ }^{4}$ Columbia University, New York, United States of America

Background: Upadacitinib (UPA) has demonstrated efficacy in randomized controlled trials ${ }^{1-3}$; however, few data are available from patients with rheumatoid arthritis (RA) who have been treated with UPA in real-world clinical practice.

Objectives: Describe the characteristics and 6-month outcomes in patients with RA initiating UPA in a real-world setting.

Methods: We identified adults with RA enrolled in the Corrona RA Registry through October 31, 2020 who initiated UPA during or after August 2019 and had a follow-up visit $6( \pm 3)$ months after initiation of UPA. Descriptive statistics were used to summarize characteristics in all patients initiating UPA who had a 6-month follow-up visit. Outcomes (CDAI, modified HAQ-DI, pain, and fatigue) were described at the 6-month visit for all UPA initiators regardless of UPA use at 6 months and for the subset of patients who continued UPA through the 6-month visit. Patients who discontinued UPA before the 6-month visit were considered non-responders for dichotomous variables and were assigned the value at the time of discontinuation for continuous variables. Mean change from baseline in continuous variables was analyzed with one-sample $t$ tests or one-sample Wilcoxon rank sum tests. Minimum clinically important difference (MCID) in HAQ-DI is defined as an improvement of 0.22 units or more. MCID in CDAl is an improvement of at least 2, 7, and 13 units for patients in low, moderate and severe disease at initiation, respectively. MCID for 100-point VAS is an improvement of $\geq 10$ points. Percentages of patients achieving MCID thresholds were calculated. Results: We identified 181 patients who initiated UPA and had a 6-month follow-up visit. Mean \pm SD age was $58.6 \pm 12.1$ years, $81 \%$ were female. Patients had RA for a mean of $11.5 \pm 9.8$ years. At UPA initiation, $45 \%$ of patients were on monotherapy. Prior use of one or more TNFi and JAKi was $79 \%$ and $52 \%$, respectively. Seventy-two percent of patients $(n=130)$ initiated UPA as the third or higher line of therapy. Mean CDAI was $18.7 \pm 11.6$ and mean HAQ-DI was $1.1 \pm 0.8$ at initiation. Based on CDAI ( $n=155), 29 \%, 52 \%$, and $15 \%$ of patients had high, moderate, and low disease activity, respectively; $4.5 \%$ were in remission at initiation. At 6 months $(n=158), 22 \%, 39 \%$, and $28 \%$ had high, moderate, and low disease activity, respectively; $11 \%$ were in remission. Among 138 initiators with valid CDAI measures at initiation and 6 months, mean change in CDAl was $-4.8 \pm 11.8, P<0.01$. At 6 months, $46 \%(63 / 138)$ maintained and $39 \%(54 / 138)$ achieved improvement in any CDAl category. Improvements in other outcomes were significantly different from zero. Improvements >=MCID in CDAI, HAQ-DI, pain, and fatigue were achieved in $36-44 \%$ of UPA initiators. Improvements were similar, but larger in the subset of patients $(n=122)$ who continued UPA through the 6 -month visit (Table 1).

Conclusion: Among patients in the Corrona RA Registry, UPA is frequently started in those who failed multiple previous therapies. UPA initiators responded to therapy in the first 6 months with improvements in several disease activity measures including CDAI and HAQ-DI, as well as patient-reported pain and fatigue.

\section{REFERENCES:}

[1] Fleischmann R. Arthritis Rheumatol. 2019;71:1788-800.

[2] Smolen JS. Lancet. 2019;393:2303-11.

[3] Burmester GR. Lancet. 2018;382:2505-12.

Acknowledgements: This study was sponsored by Corrona, LLC. Corrona has been supported through contracted subscriptions in the last 2 years by AbbVie, Amgen, Boehringer Ingelheim, Bristol Myers Squibb, Celgene, Crescendo, Eli Lilly and Company, Genentech, Gilead, GSK, Janssen, Merck, Momenta Pharmaceuticals, Novartis, Pfizer, Regeneron, Roche, Sun, UCB, and Valeant. The design, study conduct, and financial support for the study were provided by AbbVie. AbbVie participated in the interpretation of data, review, and approval of the abstract. No honoraria or payments were made for authorship.

Medical writing services were provided by Joann Hettasch of Fishawack Facilitate Ltd., part of Fishawack Health, and funded by AbbVie.
Disclosure of Interests: Joel M Kremer Shareholder of: Corrona, Consultant of: AbbVie, Grant/research support from: AbbVie, Employee of: Corrona, Namita Tundia Shareholder of: AbbVie, Employee of: AbbVie, Robert McLean Employee

Table 1.

\begin{tabular}{|c|c|c|c|c|}
\hline \multicolumn{5}{|c|}{ Outcomes at 6-month follow-up } \\
\hline & \multicolumn{2}{|c|}{$\begin{array}{c}\text { All initiators } \\
\quad(n=181)\end{array}$} & \multicolumn{2}{|c|}{$\begin{array}{l}\text { Subset remaining } \\
\text { on UPA }(n=122)\end{array}$} \\
\hline & $\mathrm{n}$ & Value $^{\mathrm{a}}$ & $\mathrm{n}$ & Value $^{a}$ \\
\hline Remission (CDAI <2.8) & 158 & $18(11)$ & 105 & $12(11)$ \\
\hline Low (CDAl >=2.8 and $<10$ ) & 158 & $44(28)$ & 105 & $38(36)$ \\
\hline Moderate (CDAl $>=10$ and $<22$ ) & 158 & $62(39)$ & 105 & $36(34)$ \\
\hline High (CDAI >=22) & 158 & $34(22)$ & 105 & $19(18)$ \\
\hline Improvement in any CDAl category & 138 & $54(39)$ & 89 & $40(45)$ \\
\hline Maintenance of CDAl category & 138 & $63(46)$ & 105 & $39(44)$ \\
\hline \multicolumn{5}{|l|}{ Mean change in } \\
\hline CDAI & 138 & $-4.8 \pm 11.8^{\star}$ & 89 & $-7.1 \pm 12.0^{*}$ \\
\hline HAQ-DI & 154 & $-0.1 \pm 0.5^{\star}$ & 101 & $-0.2 \pm 0.5^{\star}$ \\
\hline Pain & 154 & $-9.3 \pm 25.1^{*}$ & 101 & $-13.5 \pm 25.8^{*}$ \\
\hline Fatigue & 153 & $-7.6 \pm 27.3^{\star}$ & 100 & $-12.5 \pm 27.5^{\star}$ \\
\hline \multicolumn{5}{|l|}{ MCID achievement in } \\
\hline CDAI & 138 & $57(41)$ & 89 & $43(48)$ \\
\hline HAQ-DI & 154 & $55(36)$ & 101 & 39 (39) \\
\hline Pain & 154 & $68(44)$ & 101 & $53(52)$ \\
\hline Fatigue & 153 & $65(42)$ & 100 & $49(49)$ \\
\hline
\end{tabular}

${ }^{\mathrm{a}} \mathrm{Mean} \pm \mathrm{SD}$ or $\mathrm{n}(\%) .{ }^{*} P<0.01$ for improvement significantly different from zero.

of: Corrona, Taylor Blachley Employee of: Corrona, anna maniccia Shareholder of: AbbVie, Employee of: AbbVie, Dimitrios A Pappas Shareholder of: Corrona, Consultant of: AbbVie, Genentech, Novartis, Regeneron, and Roche Hellas, Employee of: Corrona

DOI: 10.1136/annrheumdis-2021-eular.170

\begin{tabular}{|l|}
\hline POS0436 \\
PATIENT CHARACTERISTICS AND OUTCOMES IN \\
PATIENTS WITH RHEUMATOID ARTHRITIS TREATED \\
WITH UPADACITINIB: THE OM1 RA REGISTRY
\end{tabular}

M. Bergman ${ }^{1}$, N. Tundia ${ }^{2}$, A. Bryant ${ }^{3}$, I. Topuria ${ }^{3}$, T. Brecht ${ }^{3}$, K. Dunlap ${ }^{2}$, A. Gibofsky ${ }^{4} .{ }^{1}$ Drexel University College of Medicine, Philadelphia, United States of America; ${ }^{2}$ AbbVie Inc, North Chicago, United States of America; ${ }^{3}$ OM1, Boston, United States of America; ${ }^{4}$ Weill Cornell Medicine, Hospital for Special Surgery, New York, United States of America

Background: Upadacitinib (UPA) has demonstrated efficacy in the treatment of rheumatoid arthritis (RA) in randomized controlled trials, ${ }^{1-6}$ but there are limited data available on its real-world use and effectiveness in patients with RA.

Objectives: To describe the characteristics and clinical outcomes at 3 months among real-world patients with RA initiating UPA.

Methods: The data source for this study was the OM1 RA Registry, a subset of the OM1 Real-World Data Cloud (OM1, Inc, Boston, MA, US), a large, linked clinical and administrative dataset derived from medical and pharmacy claims, electronic medical record data, and death data. This analysis includes data collected in patients who initiated UPA during or after August 2019. Patients had $\geq 1$ prescription for UPA (index date was first UPA prescription), were $\geq 18$ years of age at index date, had $\geq 6$ months of available data in the OM1 RA Registry prior to index date (ie, baseline period), $\geq 1$ baseline disease activity measure, and $\geq 1$ follow-up disease activity measure ( 3 or 6 months post-index). Disease activity was based on RAPID3 or CDAl. Multivariate analyses were conducted using a mixed-effects linear model adjusting for age, sex, and baseline scores. Outcomes were also assessed by therapy status (monotherapy or combination therapy) and targeted immunomodulator (TIM) use (naïve vs experienced).

Results: Inclusion criteria were met by 1,102 patients, of whom 620 were on monotherapy and 482 were on combination therapy at index. Mean age was 57.7 years, $83 \%$ were female, $75 \%$ had prior treatment with a biologic, and $47 \%$ had prior treatment with a Janus kinase inhibitor. Of 651 patients with known disease activity category, $113(17 \%)$ were in low disease activity (LDA)/remission. At baseline, overall mean \pm SD scores were $19.9 \pm 12.3$ for CDAI, $4.5 \pm 2.4$ for RAPID3, $5.7 \pm 2.8$ for pain, $5.2 \pm 3.0$ for fatigue, $3.1 \pm 2.7$ for MDHAQ Physician Global Assessment (PGA), $5.2 \pm 2.8$ for MDHAQ Patient Global Assessment (PtGA), and $3.1 \pm 2.3$ for MDHAQ Functional Index. At 3 months post-UPA initiation, mean $(95 \% \mathrm{Cl})$ change in CDAI was $-5.1(-7.5$ 
to -2.7$)$ in the monotherapy group and $-5.9(-8.7$ to -3.0$)$ in the combination group. At 3 months, $29 \%(109 / 374)$ of patients were in LDA/remission and $32 \%(120 / 374)$ of patients showed improvement in disease activity. Of 94 patients with moderate disease at baseline, $34(36 \%)$ were in LDA/remission at 3 months. Of 215 patients with high disease at baseline, 30 (14\%) were in LDA/remission and $49(23 \%)$ had moderate disease at 3 months. RAPID3 and other outcomes also improved at 3 months in the monotherapy and combination therapy groups (Figure 1). Improvements in disease activity were observed at 3 months and maintained at 6 months post-UPA initiation. Of 1,102 patients, $16 \%$ were TIM naïve and $84 \%$ TIM experienced. Both TIMnaïve and TIM-experienced patients achieved significant mean changes in CDAI $(-5.7[-10.8$ to -0.6$]$ and $-5.0[-7.0$ to -3.0$]$, respectively) and RAPID3 $(-1.0$ [ -1.6 to -0.4$]$ and $-0.5[-0.8$ to -0.1$])$ at 3 months (Table 1$)$. Improvements in clinical outcomes were maintained at 6 months in both TIM-naïve and TIM-experienced patients.

Conclusion: Significant improvements in disease activity were consistently observed at 3 months and maintained at 6 months post-UPA initiation regardless of monotherapy, combination therapy, or prior TIM use. REFERENCES:

[1] Fleischmann R. Arthritis Rheumatol. 2019;71:1788-800.

[2] Smolen JS. Lancet. 2019;393:2303-11.

[3] Burmester GR. Lancet. 2018;382:2505-12.

[4] Genovese MC. Lancet. 2018;391:2513-24.

[5] van Vollenhoven R. Arthritis Rheumatol. 2020;72:1607-20.

[6] Rubbert-Roth A. N Engl J Med. 2020;383:1511-21.

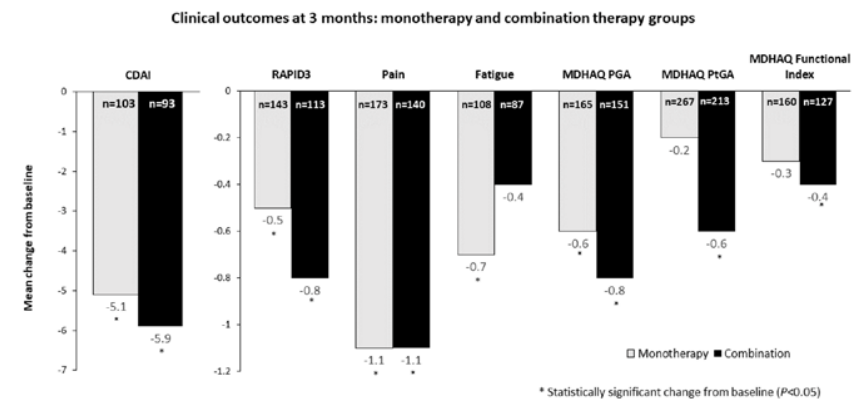

Table 1. Change in clinical outcomes from baseline at 3 months: TIM-naïve and TIM-experienced groups

\begin{tabular}{|c|c|c|c|c|}
\hline & \multicolumn{2}{|c|}{$\begin{array}{l}\text { TIM naïve } \\
(\mathrm{N}=179)\end{array}$} & \multicolumn{2}{|c|}{$\begin{array}{l}\text { TIM experienced } \\
\qquad(\mathrm{N}=923)\end{array}$} \\
\hline & $\mathrm{n}$ & Mean change & $\mathbf{n}$ & Mean change \\
\hline CDAI & 36 & $-5.7^{\star}$ & 160 & $-5.0^{\star}$ \\
\hline RAPID3 & 67 & $-1.0^{*}$ & 189 & $-0.5^{\star}$ \\
\hline Pain (VAS) & 76 & $-1.5^{*}$ & 237 & $-0.9^{*}$ \\
\hline Fatigue & 46 & -0.7 & 149 & -0.5 \\
\hline MDHAQ PGA & 65 & $-0.7^{\star}$ & 251 & $-0.7^{\star}$ \\
\hline MDHAQ PtGA & 97 & $-0.6^{*}$ & 383 & -0.3 \\
\hline MDHAQ Functional Index & 72 & $-0.7^{\star}$ & 215 & -0.2 \\
\hline
\end{tabular}

*Statistically significant change from baseline $(P<0.05)$

Acknowledgements: Funding statement: Financial support for the study was provided by AbbVie. AbbVie participated in the interpretation of data, review, and approval of the abstract. All authors contributed to the development of the publication and maintained control over the final content.

Acknowledgment:

Medical writing services were provided by Joann Hettasch of Fishawack Facilitate Ltd, part of Fishawack Health, and funded by AbbVie.

Disclosure of Interests: Martin Bergman Shareholder of: JNJ (parent of Janssen), Speakers bureau: AbbVie, Amgen, BMS, Genentech, Gilead, Janssen, Merck, Novartis, Pfizer, Regeneron, Sanofi, Sandoz, Consultant of: AbbVie, Amgen, BMS, Genentech, Gilead, Janssen, Merck, Novartis, Pfizer, Regeneron, Sanofi, Sandoz, Namita Tundia Shareholder of: AbbVie, Employee of: AbbVie, Allison Bryant: None declared, la Topuria: None declared, Tom Brecht: None declared, Kendall Dunlap Shareholder of: AbbVie, Employee of: AbbVie, Allan Gibofsky Shareholder of: AbbVie, Amgen, Horizon, J\&J, Pfizer, Regeneron, Speakers bureau: AbbVie, Acquist, Amgen, Lilly, Merck, Pfizer, Sandoz, Samumed, Consultant of: AbbVie, Acquist, Amgen, Lilly, Merck, Pfizer, Sandoz, Samumed

DOI: 10.1136/annrheumdis-2021-eular.172

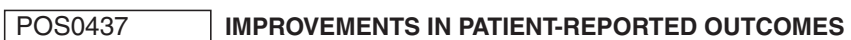
IN RHEUMATOID ARTHRITIS PATIENTS TREATED WITH GOLIMUMAB: SUB-ANALYSIS OF ASIAN PATIENTS ENROLLED IN PHASE-3 CLINICAL TRIALS

W. C. Tsai ${ }^{1}$, R. Mu' ${ }^{2}$, C. H. Suh ${ }^{3}$, D. Furtner ${ }^{4}$, K. H. Lo ${ }^{5}$, Y. Zhou ${ }^{5}$, E. C. Hsia ${ }^{6,7}$.

${ }^{1}$ Kaohsiung Medical University, Division of Allergy, Immunology, and Rheumatology, Kaohsiung, Taiwan, Republic of China; ${ }^{2}$ Peking University People's Hospital, Department of Rheumatology and Immunology, Beijing, China; ${ }^{3}$ Ajou University School of Medicine, Department of Rheumatology, Suwon, Korea, Rep. of (South Korea); ${ }^{4} J a n s s e n$, a division of Jonson \& Johnson Pte Ltd., Regional Medical Affairs, Singapore, Singapore; ${ }^{5}$ Janssen Research \& Development, LLC, Clinical Biostats, Spring House, Pennsylvania, United States of America; ${ }^{6}$ Janssen Research \& Development, LLC, Immunology, Spring House, Pennsylvania, United States of America; ${ }^{7}$ University of Pennsylvania Medical Center, Perelman Center for Advanced Medicine, Pennsylvania, United States of America

Background: Clinical efficacy and safety of Tumour Necrosis Factor-alpha inhibitor golimumab (GLM) for patients with rheumatoid arthritis (RA) and inadequate response to methotrexate (MTX) were studied in phase-3 clinical trials. A greater proportion of patients treated with GLM $50 \mathrm{mg}$ every 4 weeks (q4w) achieved improvement in clinical signs and symptoms, measured by American College of Rheumatology 20\% improvement (ACR20) response and patient-reported outcomes (PROs) when compared with placebo (PBO) at Weeks 14 and 24

Objectives: To assess PROs in RA patients from Asia treated with GLM in phase- 3 trials.

Methods: Post-hoc PRO (Health Assessment Questionnaire [HAQ], ShortForm 36 [SF-36] physical component score [PCS] and mental component score [MCS], pain, and work productivity) sub-analysis of RA patients from China (including Taiwan region) and South Korea with inadequate response to MTX randomized to subcutaneous GLM $50 \mathrm{mg}+$ MTX or PBO + MTX from 2 clinical trials (GO-FORWARD, NCT01248780).

Clinically meaningful improvement was defined as improvement of $\geq 0.25$ point in HAQ or $\geq 5$ points in SF-36 PCS and MCS. Nominal p-values were used for descriptive and exploratory purposes.

Results: At Week 24, MTX-experienced patients from Asia treated with GLM + MTX demonstrated improvements versus PBO + MTX in all PROs analyzed. Pooled patients from Asia on GLM + MTX had greater improvements at Week 24 in all measures of PROs than patients with PBO + MTX, and the improvements are comparable to all other regions (Table 1). Greater proportions of RA patients from Asia in GLM group than PBO achieved clinically meaningful improvement in HAQ, SF-36 PCS, and SF-36 MCS (Figure 1).

Conclusion: MTX-experienced RA patients from Asia treated with GLM demonstrated improved PROs after 24 weeks. The pooled results were comparable with patients enrolled from all other regions and demonstrated clinical meaningful improvements in HAQ, SF-36 PCS, and SF-36 MCS.

Table 1. Summary of Improvement from Baseline in HAQ-DI, HRQoL, Pain, and Work Productivity at Week 24: Randomized Patients in RA Studies Pooled for Regions Outside Asia and Randomized Patients from Asia

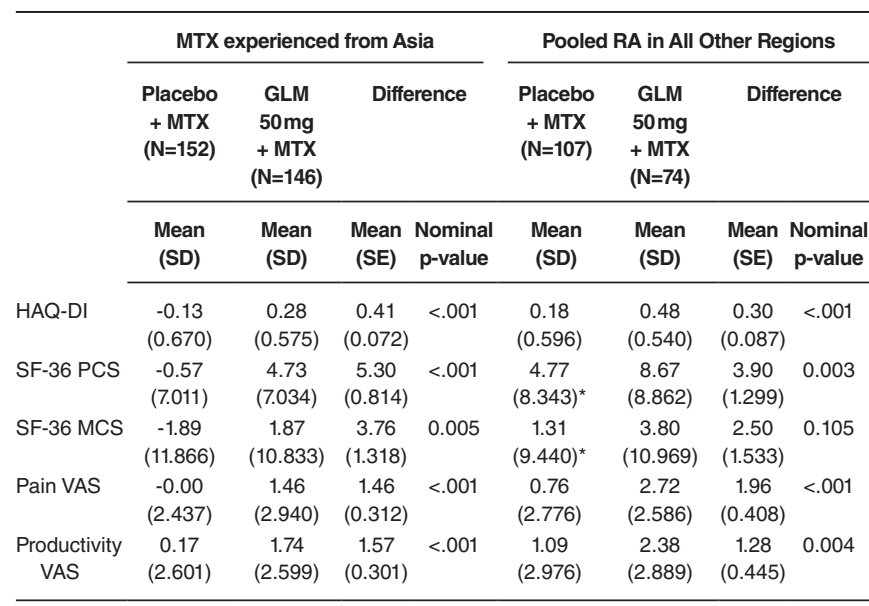

GLM, golimumab; HAQ-DI, health assessment questionnaire disability index; HRQoL, health-related quality of life; MTX, methotrexate; RA, rheumatoid arthritis; SD, standard deviation; SE, standard error; SF-36 MCS, short-form 36 mental component score; SF-36 PCS, short-form 36 physical component score; VAS, visual analogue scale* $\mathrm{N}=105$ 